\title{
GESTIÓN FINANCIERA DE EMPRESAS EN CRISIS "LA REALIDAD PERUANA"
}

Miguel Nicolás Díaz Inchicaqui* Ricardo Garcia Castro**

\section{INTRODUCCIÓN}

Nuestra investigación: Gestión financiera de empresas en crisis "La Realidad Peruana", en primer lugar estudia y analiza las variables extemas que gravitaron en la crisis de los diversos sectores productivos de nuestra economía; tales como: las políticas económicas implementadas por los gobernantes de turno, la corrupción a nivel político e institucional, el terrorismo, los desastres naturales que devastaron nuestro país, etc. Asimismo, también consideramos los efectos de las crisis financieras internacionales ocurridas en México, Asia, Rusia, Brasil, Argentina y por último la globalización económica internacional en la economía peruana.

También analizamos un conjunto de variables de origen internas que han sido los agentes que causaron crisis financiera en las empresas nacionales, tales como: los sistemas productivos ineficientes, la inversiones improductivas, la falta de competitividad, la resistencia al cambio de las personas que laboran en las empresas, alta morosidad del sistema financiero provocada por la recesión económica, endeudamiento con el costo financiero elevado, estrategias implementadas inadecuadas, constitución y organización en mayor porcentaje de tipo familiar

La tesis central de nuestra investigación es la elaboración de un Plan Estratégico para gestionar empresas en crisis, considerando la trilogía básica del gestor: la supervivencia, crecimiento y utilidad, pasando por una etapa de diagnóstico que zonsidere el acuerdo concursal entre el que va a gestionar la empresa en crisis y los acreedores, los mismos que deben ser identificados plenamente en esa etapa.

Por último, consideramos también importante analizar y evaluar el sistema peruano de reestructuración patrimonial, que tiene más de nueve años de vigencia y por el cual han pasado empresas de todos los sectores económicos; de diferentes tamaños, distinto número de trabajadores, variados niveles de endeudamiento y variadas razones para ingresar al sistema ya sean éstos por problemas coyunturales o estructurales.

\section{VARIABLES QUE CAUSARON LA CRISIS EMPRESARIAL ENEL PERÚ}

\subsection{Causas con origen externo a las empresas}

Una de las causas más gravitantes que originó la crisis empresarial en el Perú, fueron los modelos económicos aplicados por los gobernantes de tumo en las últimas décadas, esto lo explicaremos de manera muy resumida analizando modelos económicos que se aplicaron en estos últimos 50 años.

Entre el período denominado liberal 1950 -1969 y el llamado proteccionista entre 1970 1990 , observamos una notable diferencia en la evolución del PBI per capita y la tasa de inflación. En-el período liberal la tasa de crecimiento promedio anual del producto per cápita fue del $3 \%$, mientras que en el período proteccionista fue de $0,4 \%$, declinándose aún más dicho producto a partir de 1988. La tasa de

\footnotetext{
- Profesor Auxiliar de la Facultad de Ciencias Contables
}

- Profesor Auxiliar de la Facultad de Ciencias Contables 
inflación fue de un promedio de $9 \%$ en el período liberal, incrementándose a $56 \%$ en el período proteccionista $1970-1987$, ya que a partir de 1988 el Perú experimentó un proceso hiperinflacionario e hiperrecesivo no registrado en la historia peruana de los últimos 50 años. Estos cambios de modelos económicos del liberal al proteccionista ahondaron en cambios de la estructura productiva hacia bienes sustitutos de productos importados (iniciada en el período liberal), creándose de esta manera mecanismos que originaron el estancamiento o crecimiento económico del país.

A partir del año 1990 se implemento dos tipos de políticas, una para atacar los problemas de corto plazo, mediante el denominado "programa de estabilización" la cual debía combatir la inflación, el déficit fiscal y la falta de divisas; y la segunda, denominada "reformas estructurales o proceso de liberalización de la economía", la cual planteaba un modelo de crecimiento para la economía peruana. Los resultados son conocidos, el programa de estabilización cumplió con sus objetivos trazados, sin embargo, el modelo de crecimiento económico no llegó a obtener los resultados planificados por las siguientes causas:

- Las políticas económicas de corto plazo y largo plazo fueron diseñadas en función de la estabilización y no en función del crecimientoeconómico.

- Las políticas de estabilización se mantienen con una consecuencia lógica que es la destrucción del aparato industrial doméstico.

- La liberalización financiera ha implicado aumentos significativos de la tasa de interés reales, con los consecuentes y negativos efectos sobre los precios, la producción y rentabilidades de los agentes económicos.

- La política de equilibrar el presupuesto ha generado un uso excesivo de los impuestos indirectos que incrementan los costos de producción y disminuyen las rentabilidades de los agentes económicos.

Como observamos, la falta de crecimiento económico y social del país afecta directamente a los diferentes sectores económicos y por ende a las empresas, por las causas de cambios de modelos y políticas económicas implementadas el mismo que tiene a la fecha de nuestra investigación como resultado una economía recesiva, que ha conducido a una crisis financiera generalizada casi a la totalidad del aparato productivo nacional, ya que tampoco en la última década se pudo concretar un crecimiento económico sostenido por las contradicciones entre las políticas de estabilización y de crecimiento, por el contrario estamos ante un escenario donde los problemas de extrema pobreza se han ahondado además de mantenerse latentes las causas de la violencia social.

El efecto de la globalización económica internacional, en la economía peruana podemos resumirlo como aquel fenómeno que trajo grandes beneficios a la economía global, sin embargo hay preocupaciones reales, de que la globalización viene causando dolorosas dislocaciones laborales y exacerbando aún más la brecha entre ricos y pobres.

Por último también hemos analizado cómo las crisis internacionales afecta a las economías de mercado emergentes como el Perú tal como sucedió durante la segunda mitad de los años noventa. Aunque tales crisis no eran de ninguna manera un nuevo fenómeno, lo que atrajo atención especial a los recientes episodios fue la percepción de una posibilidad elevada de contagio el derrame exterior de las presiones de un país en crisis a otros países. El riesgo de tal contagio se hizo evidente cuando al derrumbarse la moneda en Tailandia se activó una cascada de crisis en otros mercados emergentes asiáticos. Las presiones también podrían extenderse a través de los mercados financieros mundiales a las economías industriales, como sucedió con la crisis financiera rusa. 


\subsection{Causas de origen interno o de las em- presas en crisis}

La organización empresarial en el Perú no es competitiva, por la afectación primaria de las variables externas que hemos analizado, ya que ser competitivos significa poseer la capacidad de mantener sistemáticamente ventajas comparativas que le permitan alcanzar, sostener y mejorar una determinada posición en el entorno socioeconómico que se desarrolla. Para explicar mejor dicha ineficiencia, consideremos los niveles de competitividad, tanto interna como la externa. La competitividad interna se refiere a la capacidad de organización para lograr el máximo rendimiento de los recursos disponibles, como personal, capital, materiales, ideas, etc., y los procesos de transformación.

Las crisis económicas, los problemas de mercado, la tendencia de los precios y el proceso de apertura que vive nuestro país, han obligado a las empresas a tener nuevos y mejores enfoques en sus niveles administrativos, ya que sus directivos buscan mejores tecnologías que ayuden a mejorar el rendimiento de sus empleados; todo esto con ayuda de estrategias de calidad y mejoramiento continuo. La resistencia al cambio, en un proceso de crisis empresarial tiene que ser crucial, sino los esfuerzos que se realicen en los negocios no podrán soportar ambientes desafiantes y mercados altamente competitivos.

\section{ELABORACIÓN DEL PLAN DE GES- TIÓN FINANCIERA DE EMPRESAS EN CRISIS}

Las empresas como las personas, pueden encontrarse sanas y luego caer enfermas o en crisis. En el caso de las personas éstas visitan a un médico se les somete a diversas pruebas y se les recomienda un tratamiento. En el caso de las empresas es análogo, el gerente o dueño visita a un gestor de empresas en crisis que le recomienda una reformulación formal de la organización y el monitoreo hasta sacarlo de la crisis en que se encuentra la empresa.
2.1. El Diagnóstico, el primer paso del consultor será conocer la situación actual de la empresa, es decir, responder a las siguientes preguntas: ¿cómo está la empresa?, ¿hay posibilidad de salvarla? Para esto debemos contactarnos con el responsable del manejo de la empresa el gerente o propietario.

Para un diagnóstico adecuado debemos utilizar los siguientes métodos: las narrativas o descriptivos que se efectúan en el alto nivel de la organización empresarial, ya que son ellos, como responsables, los que conocen de cerca la situación actual de la empresa; también podemos usar cuestionarios ya que esté permite indagare identificar, el nivel de dificultad que se tenga en un área o actividad determinada. Entre los cuestionarios que debemos formular para determinar un diagnóstico adecuado tenemos:

- Producto que produce o comercializa la empresa

- La empresa y los compradores

- Los clientes y la organización para el mercadeo

- Métodos de fabricación, el control de producción y calidad

- Compras y control de existencias

- Recursos humanos

- Personal

- Contabilidad y estadística

- Aspectos financieros y el futuro de la empresa

Al final de cada cuestionario se deberá anotar el promedio cuantitativo que resulte de las respuestas anotadas en las columnas de medición, con la finalidad de elaborarel cuadro Resumen de la Situación Actual de la Empresa. 


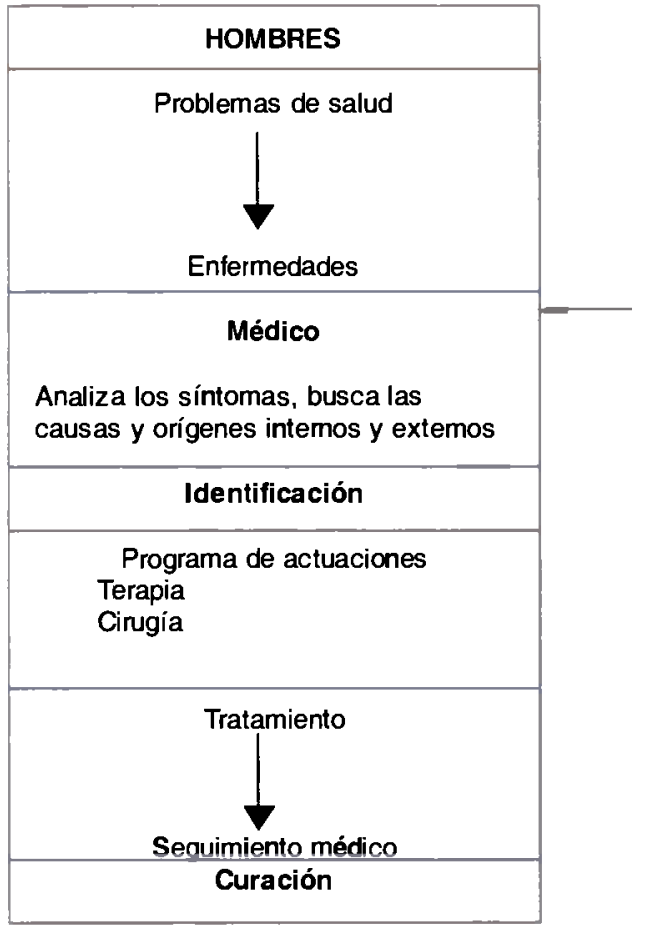

El diagnóstico es una herramienta al servicio de la voluntad de control y progreso de factores que caracterizan una gestión eficaz.

EI diagnóstico financiero, es fundamental para formular todo Plan de Gestión Financiera de empresas en crisis, su importancia radica en que la salida definitiva a los problemas que aquejan a las empresas es su saneamiento financiero, comercial y administrativo.

Desde el punto de vista financiero se deberá obtener la siguiente información:

- Conocer a la empresa en marcha, su potencial para el futuro y los elementos que lo sustentan tales como: mercado, producto, calidad y eficiencia de la gerencia y del personal, efectividad de los sistemas de información y de los controles internos implementados.

- Conocer la situación financiera patrimonial, legal y tributaria de la compañía. Es decir, buscamos conocer si los activos son de libre disponibilidad, si los pasivos registrados son suficientes, los compromisos de la compañía ante

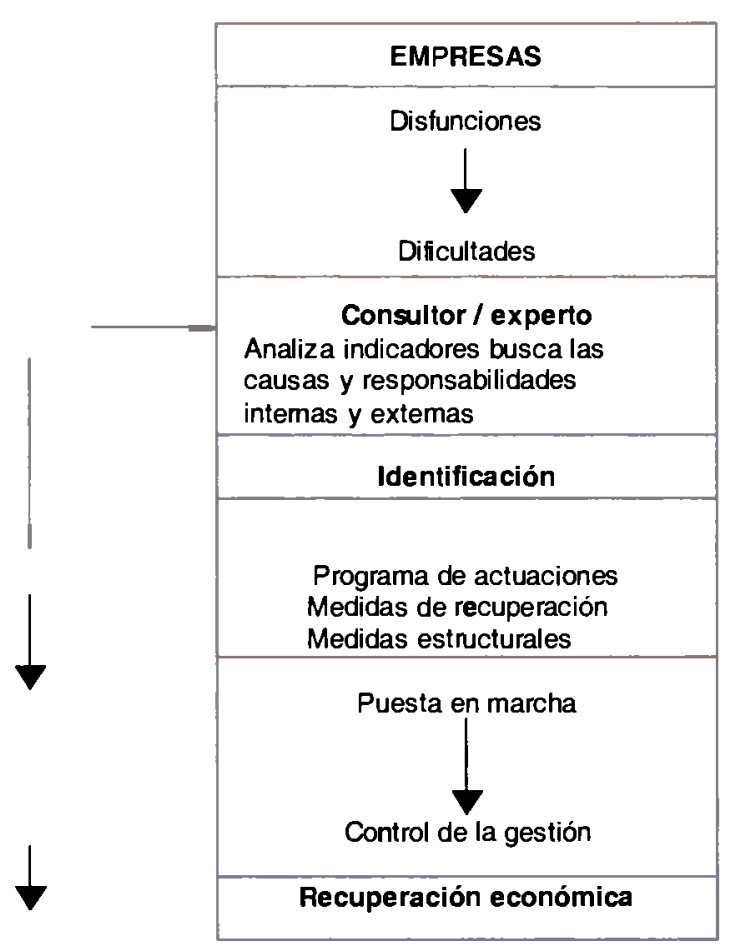

terceros y las contingencias tributarias, laborales, del medio ambiente y si los reclamos de terceros en general están debidamente registrados y expuestos en los estados financieros.

- Como consecuencia del diagnóstico financiero debemos identificar aspectos como la omisión de pago de pasivos que podrían afectar en el futuro del negocio y agravar su situación financiera real; entre estos pasivos tenemos:

- Los pasivos identificados aquellos que están expuestos en los estados financieros y que a la fecha del diagnostico aún no han sido cancelados afectando esta situación el precio del producto que comercializa la empresa, entre estos pasivos tenemos las deudas tributarias, laborales, letras vencidas, etc.

- Los pasivos ocultos, aquéllos que no se exponen en los estados financieros tales como los juicios de responsabilidad por daños al medio ambiente, reclamos de trabajadores que ya no laboran en la empresa, pactos con terceros no declarados, etc; éstas al igual que los 
pasivos identificados afectan el precio del producto que comercializa la empresa.

- Las contingencias son aquellas situaciones que podrían presentarse o no pero que requieren de una garantía real o personal, o bien que parte del precio quede en una cuenta garantía para hacerles frente si se presentan.

\subsection{El Plan de Gestión Financiera (PGF)}

El Plan de Gestión Financiera (PGF), de empresas en crisis debe considerar como mínimo tres tipos de acciones:

- El refuerzo: que viene a ser la acción de atenuar las causas y debilidades del negocio que lo condujeron a la crisis financiera, tales como: el organizativo, estructural, ineficiencia de los costos, etc.

- El redespliegue: que viene a ser la acción de migrar a otros mercados y/o productos donde probablemente se pueda ser competitivo.

- La acción política: presión a gremios, a los acreedores y al público en general, con la finalidad de buscar cambios en los factores externos que afectan esta crisis.

Para la ejecución del Plan, debemos de contar con un equipo capaz de gerenciar la crisis, haber definido si se venden activos abandonados con la finalidad de buscar dinero fresco y levantar la caja de la empresa en crisis, haber sido capaces de reestructurar la deuda pendiente que agobia a la empresa, haber definido el nivel de gastos acorde con el nivel de operatividad que se tenga y por último siempre es importante no perder la credibilidad ni del grupo humano que labora en la empresa ni de los clientes, entidades financieras, estado etc.

En el PGF se debe fijar adecuadamente los objetivos del Plan fijándose claramente las estrategias para "darle la vuelta" a una empresa, pasando de una etapa de crisis a una de reflotamiento o de indicadores financieros en rojo a azul, tales como: Rentabilidad: margen operativo, utilidad neta, rotación; Solvencia: grado de propiedad, palanqueo financiero; y Liquidez: flujo de caja neto, relación corriente, grado de propiedad comente.

Asimismo, el PGF debe detallar las políticas implementadas para la reducción de costos, la reestructuración de deudas pendientes, la recapitalización, el control desarrollado por una gerencia profesional.

\section{EL SISTEMA DE REESTRUCTU- RACIÓN PATRIMONIAL PERUANO}

El 30 de diciembre de 1992, se publicó el Decreto Ley No 26116 denominada "Ley de Reestructuración Empresarial”, mediante esta norma se incorpora al ordenamiento legal el más moderno sistema dentro del derecho concursal o de quiebras.

Este Decreto Ley posibilita la continuidad de las actividades productivas de las empresas, viabilizando el pago de los acreedores y eliminando el costo social y la pérdida de empleos que se generaba como consecuencia de la aplicación de un sistema basado en los juicios de quiebra. Con esta norma se estableció el régimen aplicable de tratamiento de las empresas en estado de insolvencia, creando el mecanismo de Reestructuración de las empresas viables y eliminando barreras que impiden u obstaculizan la salida del mercado.

Igualmente mediante esta norma se creó "La comisión de simplificación del acceso y salida del mercado", como órgano funcional de "Indecopi", y que las funciones de esta comisión, entre otras, era la de supervisar para que no se opongan barreras burocráticas que impidan u obstaculicen la salida de las empresas de la actividad económica, velando por el cumplimiento de las disposiciones contenidas en la ley de reestructuración empresarial.

Después de tres años de aplicación de la ley de reestructuración empresarial, el gobierno creó conveniente y de necesidad efectuar 
determinadas modificaciones en la legislación concursal, con el fin flexibilizar los mecanismos de reestructuración, principalmente en lo que se refiere a la participación del Estado, en su condición de acreedor tributario, en los procedimientos y completar la legıslación para que su aplicación alcance a las personas naturales.

Por tal motivo se promulgó el $21 \mathrm{de}$ setiembre de 1996 el Decreto Legislativo $N^{\circ} 845$ "Ley de Reestructuración Patrimonial", quedando derogado el Decreto Ley N. ${ }^{\circ} 26116$.

Entre los objetivos específicos del Sistema de Reestructuración Patrimonial tenemos:

a) Protección a las empresas y personas naturales que se encuentran en dificultades económicas y financieras. b) Es una herramienta para enfrentar la crisis económica.

c) Para que las empresas viables permanezcan en el mercado, bajo la libre competencia.

d) La posibilidad de reflotamiento de las empresas viables.

e) Una nueva visión de ver el reflotamiento de las empresas, tomando en cuenta a los trabajadores, clientes, proveedores, estado y los accionistas o dueños.

Es importante mencionar que en los nueve años de vigencia del Sistema de Reestructuración Patrimonial, hasta la fecha se han obtenido los siguientes resultados:

\subsection{Empresas en el Sistema de Reestructuración Patrimonial ${ }^{1 / 2}$}

\subsubsection{Empresas acogidas al Sistema}

(1993- enero 2002)

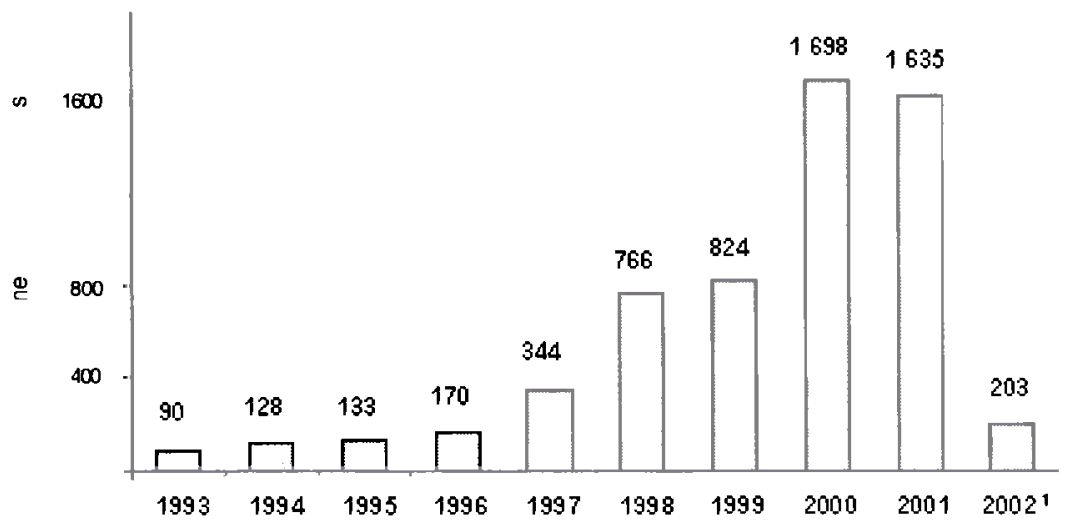

1/A enero del 2002

Fuente: Comisión de Reestructuración Patrimonial del Indecopi

Elaboración: Gerencia de Estudios Económicos del Indecopi 


\subsection{Reconocimiento de créditos:}

3.2.1. Monto de créditos reconocidos en el sistema (1993 - enero 2002)

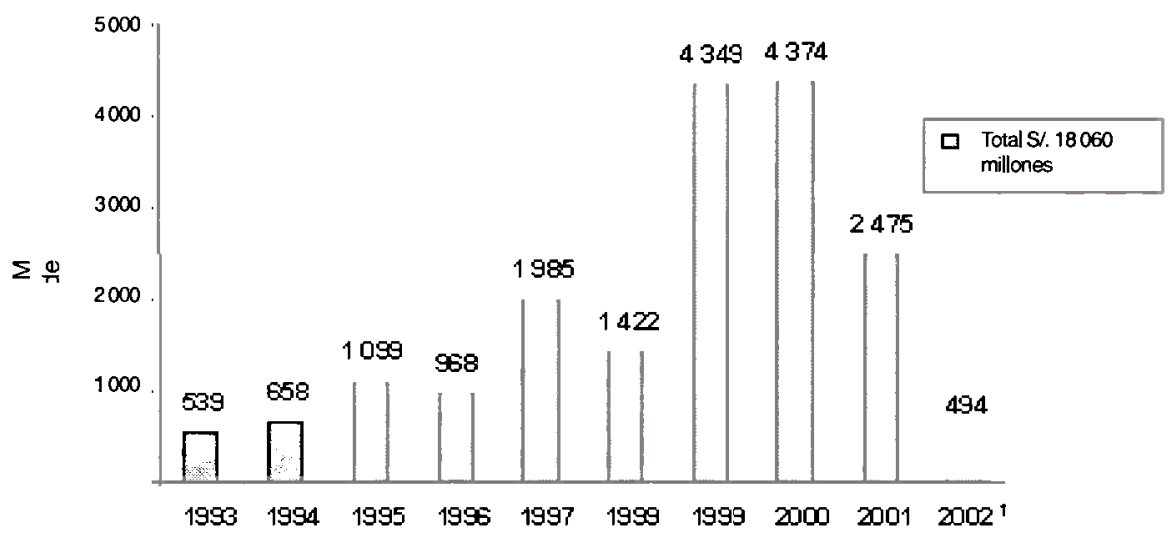

1/A enero del 2002

Fuente: Comisión de Reestructuración Patrimonial del Indecopi

Elaboración: Gerencia de Estudios Económicos del Indecopi

\subsubsection{Monto de créditos reconocidos por el Procedimiento de insolvencia por} tipo de decisión ${ }^{1 /}$

(1993 - enero 2002)

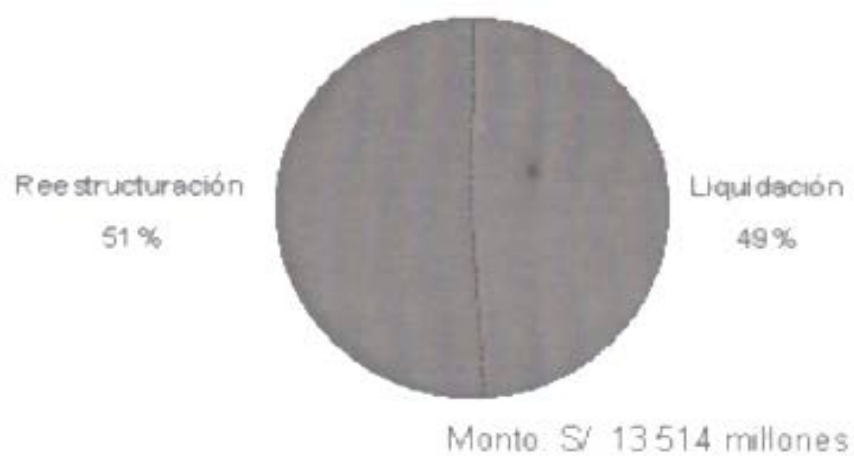

1/ No incluye Juntas instaladas que aún no tienen decisión de destino de la empresa

Fuente: Comisión de Reestructuración Patrimonial del Indecopi

Elaboración: Gerencia de Estudios Económicos del indecopi 


\subsubsection{Monto de créditos reconocidos en el Sistema por sector económico (1993 - enero 2002)}

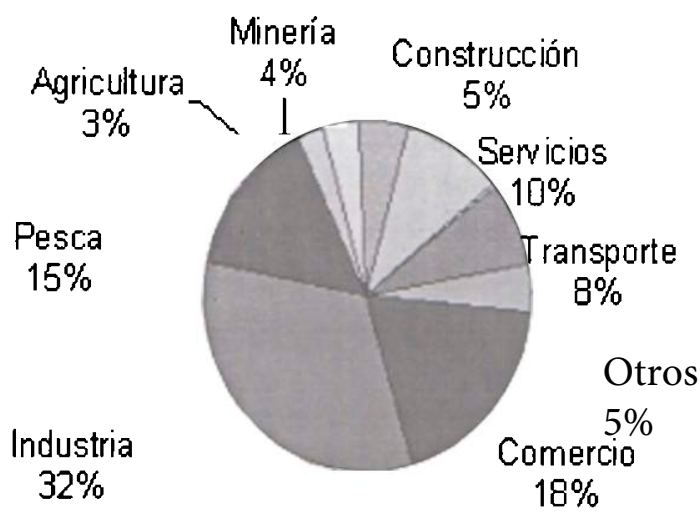

Monto: S. 18363 millones

1/ incluye personas naturales sin actividad empresarial

Fuente: Comisión de Reestructuración Patrimonial del Indecopi

Elaboración: Gerencia de Estudios Económicos del indecopi

Esta situación real nos indica que las normas de reestructuración no han tenido el efecto positivo para salvar a las empresas en crisis debido a los siguientes factores que consideramos:

Algunos empresarios recurren a solicitar la insolvencia de su empresa, después de haberla descapitalizado, inclusive con apropiación de los activos fijos en complicidad con terceros, para crear otra empresa.

Los encargados de la gestión de las empresas no tienen la experiencia y visión de las nuevas formas técnicas y científicas de hacer empresa y no toman las medidas oportunas para corregir y enmendar las dificultades que atraviesa la empresa.

\section{CONCLUSIONES}

- Nuestra investigación al haber analizado las variables que afectan económica y financieramente los diferentes sectores productivos y de servicios, llega a la conclusión que la crisis empresarial en el Perú se mantendrá a niveles elevados, porque los gobernantes de turno no muestran cambiar sustantivamente en la forma de hacer política económica. En nuestro planteamiento de cambio sugerimos que las políticas de corto y largo plazo deben diseñarse en función de crecimiento económico sostenido de toda la economía nacional, no debe considerarse sólo la estabilización; el gobierno debe intervenir con mecanismos de mercado y fuera de mercado para superar las distorsiones existentes del liberalismo y globalización.

- Habiéndose incrementado la cantidad de empresas en crisis, también hemos llegado a la conclusión que el sistema peruano de reestructuración patrimonial, adolece de fallas de diseño ya que no está facilitando la salida del mercado de las empresas claramente insolventes, por el contrario está frenando la asignación y reasignación de los escasos recursos económicos del sistema financiero, perturbando seriamente la estabilidad monetaria nacional.

- En la realidad peruana las empresas aún no han normalizado con mayor o menor éxito un modelo de diagnóstico económico financiero, utilizado por el analista para la toma de decisiones tanto en el ambiente interno como externo. Hoy en día, el alto 
índice de morosidad que arroja el sistema financiero conlleva que las técnicas de predicción o evaluación del riesgo sean lo más objetivos y certeras posibles en ese sentido, el presente trabajo busca desarrollar un marco conceptual que permita abordar convenientemente la teoría económica de la insolvencia.

- El gestor de una empresa en crisis debe preparar un Plan de Gestión Financiera, donde aborde objetivamente los problemas y variables para detener la caída e iniciar la recuperación mediante un proceso de reestructuración financiera que tendrá como objetivo mantener a raya a los numerosos acreedores, preservar y reducir la carga del servicio de la deuda, aumentar la liquidez, convertir de ser posible la deuda en capital, buscar un consenso entre los acreedores para no liquidar la empresa, ya que los efectos sociales y económicos son graves en un país como el nuestro donde lo fundamental es la generación de puestos de trabajo a través de empresas competitivas que ayuden al desarrollo del país.

\section{BIBLIOGRAFÍA}

Boloña Behr, Carlos. Experiencias para una economía al servicio de la gente. Perú, 2000.

De Cossio, José Luis. Crisis Empresarial. Lima, Ediciones Cossio, 1995.

Decreto Legislativo N. ${ }^{\circ} 845$ "Ley de Reestructuración Patrimonial" del 21 de setiembre de 1996.

Decreto Superior N. ${ }^{\circ}$ 044-93-EP "Reglamento de la Ley $26116 "$ del 23 de marzo de 1993.

Decreto Supremo N. ${ }^{\circ}$ 014-99/JTINCI "Texto Único ordenado de la Ley de Reestructuración Patrimonial" del 01 de noviembre de 1999.
Decreto de Urgencia N. ${ }^{\circ}$ 064-99 "Establecer Normas Transitorias para al desarrollo de Programas de saneamiento y fortalecimiento patrimonial en las empresas" del 01 de diciembre de 1999.

Drucker Peter. La gerencia del futuro. Colombia, Edit. Norma, 1996.

Hammer, Michael y Champy, James Reingeniería. Grupo Editorial Norma, 1996.

INDECOPI Recopilación ordenada de las leyes del INDECOPI. Edit. Lima, 1996.

INDECOPI Seis Experiencias empresariales de reeestructuración patrimonial. Lima, 2000.

Ivancevish J.M; Lorenci, Peter y Crosby Philip. Gestión, calidad y competitividad. Edit. Irwin, 1996.

Ley 27146 "Ley de fortalecimiento del sistema de reestructuración patrimonial", del 23 de junio de 1999.

Ley 26116 "Ley de reestructuración Empresarial", del 30 de diciembre de 1992

Manrique. R, Francisco. Un cambio de época de cambios. La gerencia latinoamericana debe cambiar. Colombia, Editorial Norma, 1993.

Muñoz, Estuardo Rodas. Reestructuración patrimonial. Lima, Edit. Rhodas, 1997.

Nueno, Pedro Reflotando la empresa. Edic. Deustuo, 1991.

Porter, Michael. Ventaja competitiva. México, compañía Edit. Continental,1987.

Senge. M, Peter. Laquinta disciplina. México, Compañía Edit. Continental, 1987

Sotner, James R.F. Administración. México, Edit. Prentice Hall Hispanoamericana, 1996.

Thorner, Paul. El nuevo gerente general. Colombia, Edit. Mc Graw- Hill,1997.

Yip, George S. Globalización: estrategias para obtener una ventaja competitiva internacional. Editorial Norma, 1993. 